\title{
New developments in asbestos-related pleural disease
}

\author{
Robin M Rudd
}

Asbestos causes several types of benign pleural disease, the best recognised of which is pleural plaque formation. Diffuse pleural thickening is a more serious consequence of exposure to asbestos and this often first appears as a sequel to benign pleural effusion associated with asbestos-induced pleurisy.

\section{Pleural plaques}

Pleural plaques are discrete raised areas which may be situated on the parietal pleura on the chest wall, diaphragm, pericardium, and mediastinum. They are strongly associated with exposure to asbestos although they are also found in subjects from whom no history of exposure can be elicited. They occur after inhalation of all types of asbestos although anthophyllite appears to be the most potent. Plaques occur with increased frequency in populations living in areas where the soil is contaminated with asbestiform minerals - for example, in areas of Finland, Bulgaria, Czechoslovakia, and Greece - and in those living in proximity to asbestos mines or factories. Plaques may occur after slight asbestos exposure but in occupationally exposed groups the prevalence of plaques increases with increasing dose of asbestos inhaled, ${ }^{1}$ continues to increase more than 40 years after first exposure to asbestos, ${ }^{2}$ and is not affected by smoking. ${ }^{2}$ Pleural plaques are rarely seen in persons under 40 years of age, ${ }^{3}$ which is consistent with observations that they are not found less than 10 years - and seldom less than 20 years - after first exposure to asbestos. ${ }^{4}$ Pleural calcification rarely occurs less than 20 years after first exposure to asbestos. ${ }^{5}$

The route by which asbestos fibres reach the parietal pleura is not known for certain. Asbestos fibres deposited in the peripheral parts of the lung tissue probably penetrate the visceral pleura to be carried in the pulmonary lymphatic system to the visceral pleural surface. It is theoretically possible that sharp fibres could penetrate the visceral pleura and pass directly into the parietal pleura, there to cause tissue damage which eventually results in the formation of a pleural plaque. This seems unlikely because the formation of plaques is not preceded by evidence of an inflammatory pleurisy and the visceral pleura immediately opposite a parietal pleural plaque usually looks normal.
Moreover, chrysotile is the major fibre type found in the parietal pleura, ${ }^{67}$ rather than the needle-like amphiboles which would be more likely to penetrate the pleura in this way. It is possible that fibres may pass via the lymphatic system from the lung, through the lymphatic circulation to the intercostal and diaphragmatic lymph vessels. From these vessels the fibres could reach the parietal pleura and be deposited, thereafter causing plaques to develop. This theory requires that fibres should travel against the normal flow of lymph, but this appears to be possible as coal dust can be found in intercostal lymphatics. ${ }^{8}$

Sebastien and colleagues, using transmission electron microscopy (TEM), studied the fibre content of parietal pleural plaques and normal parietal pleura and compared the results with those in lung tissue from the same subjects who had various conditions possibly related to asbestos exposure. ${ }^{6}$ Asbestos fibres were found in the parietal pleura in 16 of 29 cases, whereas fibres were found in 27 of 29 lung tissue samples. When a pleural sample was positive for asbestos fibres almost all the fibres were chrysotile and they were shorter than chrysotile fibres from the lung tissue. Significant quantities of amphibole fibre were found in the pleura in only one of the 29 cases, whereas in lung tissue a mean of $56 \%$ (range $0-100 \%$ ) of fibres were amphiboles. Churg and Vedal have recently reported, on the basis of multiple regression analysis of data from TEM of lung tissue, that plaques are associated with fibres of higher aspect ratio (length/width) than mesothelioma. ${ }^{9}$

Necroscopic studies show that plaques of minor extent are frequently not detected by radiological examination. ${ }^{10}$ Computed tomographic scanning demonstrates the extent of pleural plaques more accurately than does a plain radiograph. Multiple plaques visually superimposed upon each other may be impossible to distinguish from diffuse pleural thickening on the plain radiograph, but computed tomographic scanning allows differentiation. ${ }^{11}$

Pleural plaques do not usually cause enough impairment of lung function to give rise to symptoms, although occasionally their extent is sufficiently great for the plaques to fuse to form sheets which can interfere with the expansion of the lungs by making the chest wall stiff and resistant to movement. Plaques 
are frequently associated with evidence of limitation to airflow in the small airways $s^{12-16}$ and with a minor reduction in vital capacity. ${ }^{17} 18$ Most asbestos workers are or have been smokers, and this probably contributes to the airflow limitation. However, airflow limitation in small airways has been observed even in non-smokers, ${ }^{13}$ and it is probably the functional counterpart of asbestos airway disease. A study of 36 long term chrysotile miners without asbestosis found evidence of severe diffuse small airway abnormalities. ${ }^{19}$

Pleural plaques have some prognostic significance. Among persons found to have plaques who have sustained substantial exposure to asbestos there is a risk that clinically obvious asbestosis will develop in the future. Of 155 dockyard workers who were re-examined 10 years after detection of benign pleural changes, 10.3\% had radiographic small parenchymal opacities suggestive of asbestosis and $4.5 \%$ had both clinical and radiological signs of asbestosis. ${ }^{20}$ The attack rate was substantially higher than among men with no initial pleural abnormality.

Pleural plaques are not themselves precursors of malignant change but, in so far as they reflect exposure to asbestos, they may be associated with an increased risk of asbestosrelated malignancy. In most cases of both pleural and peritoneal mesothelioma radiological evidence of benign pleural disease is also present and is likely to have antedated the development of mesothelioma. ${ }^{21}$ The relation between pleural plaques and lung cancer is not entirely clear. A study of shipyard workers in the UK found a significant excess of deaths from both lung cancer and mesothelioma in those with plaques compared with unexposed controls matched for age and sex. ${ }^{22}$ However, this study was potentially flawed by selection bias. A recent review of evidence from several studies concluded that studies which supported an increased risk of lung cancer in those with plaques were the most subject to selection bias. ${ }^{23}$ It was concluded that there is no convincing evidence that the presence of pleural plaques is predictive of an increased risk of lung cancer. However, each of the studies available for review was unsatisfactory in one or more respects; they concerned populations with unknown or low level exposure to asbestos and/or a low incidence of asbestos-related lung cancer, control for the effects of smoking was often unsatisfactory, latency was often ignored, and follow up was often incomplete. On a priori grounds it seems likely that the risk of lung cancer will be a function of the dose of asbestos inhaled rather than the presence or absence of plaques.

\section{Acute pleurisy and pleural effusion}

Benign asbestos pleurisy is a manifestation of asbestos-induced disease that is sometimes forgotten, although it has been well recognised since the early $1960 \mathrm{~s} .{ }^{24} \mathrm{~A}$ recent study showed that a history of exposure to asbestos was significantly more common in subjects with "idiopathic" pleural effusion than in control subjects. ${ }^{25}$ In a series of 20 cases in asbestos insulation workers the effusion occurred an average of 26 years after first exposure to asbestos, but in four cases it was seen after an interval of less than 10 years. ${ }^{26}$

Injection of crocidolite into the pleura of the rabbit induces chemotactic activity resulting in a polymorphonuclear effusion. The process is not dependent on complement activation but is probably a result of a direct effect of the fibres on pleural tissue. ${ }^{27}$ The pathology is that of an acute exudative pleurisy.

In humans pleural aspiration usually reveals an exudate which is often bloodstained even in the absence of malignancy, and it is important to recognise that the finding of a bloodstained effusion in an asbestos worker does not necessarily imply mesothelioma. Pleural biopsy samples show only non-specific pleural inflammation and fibrosis. Asbestos bodies or fibres are rarely evident by light microscopy although sparse fibres, usually chrysotile, may be seen in the pleura by electron microscopy.

Pleural aspiration relieves breathlessness and anti-inflammatory analgesics relieve pain. Spontaneous resolution of each episode is usual, but the condition may be recurrent with increasing diffuse pleural thickening after each episode. ${ }^{26}$ Occasionally mesothelioma emerges some years after what at first seemed to be a benign effusion. ${ }^{27}$

\section{Diffuse pleural thickening}

Diffuse pleural thickening is a type of pleural fibrosis which extends continuously over a variable proportion of the thoracic cavity. There are frequently adhesions between the parietal and visceral pleurae. Diffuse pleural thickening is a less common manifestation of exposure to asbestos than pleural plaque formation. The incidence increases with increasing time after first exposure. ${ }^{28}$ Its occurrence is dose related ${ }^{28}$ although less clearly so than asbestosis or the malignant diseases. ${ }^{29} 30$

A wide range of fibre counts is observed in association with the condition. ${ }^{31}$ Among 12 cases with diffuse pleural fibrosis studied by Gibbs $e a^{32}$ the mean total asbestos fibre count was 89 million fibres/g dried lung (calculated from data in tables 2 and 3 in the paper, averaging counts from central and subpleural regions). This may be compared with mean total fibre counts of $42,59,343$, and 2550 million/g dried lung (including, respectively, $34 \%, 24 \%, 18 \%$, and $7 \%$ non-asbestos fibres) in cases of histologically defined minimal, slight, moderate, and severe asbestosis quoted in another study in which the analyses were performed in the same laboratory. ${ }^{33}$ The levels in cases with diffuse pleural fibrosis are thus of a similar order of magnitude to those in cases of mild to moderate asbestosis and substantially greater than those found in control subjects for example, geometric mean chrysotile $1 \cdot 4$, amosite 0.02 , and crocidolite $0.02 \mathrm{million} / \mathrm{g}$ dried lung in 55 control subjects reported by Gibbs et al. ${ }^{32}$ In the lung tissue of subjects with diffuse pleural fibrosis levels of amphibole fibre exceeded those in control subjects to a substantial degree, whereas chrysotile levels were increased to a lesser degree. ${ }^{32}$ Fibre levels in the pleura were much lower than in the lung 


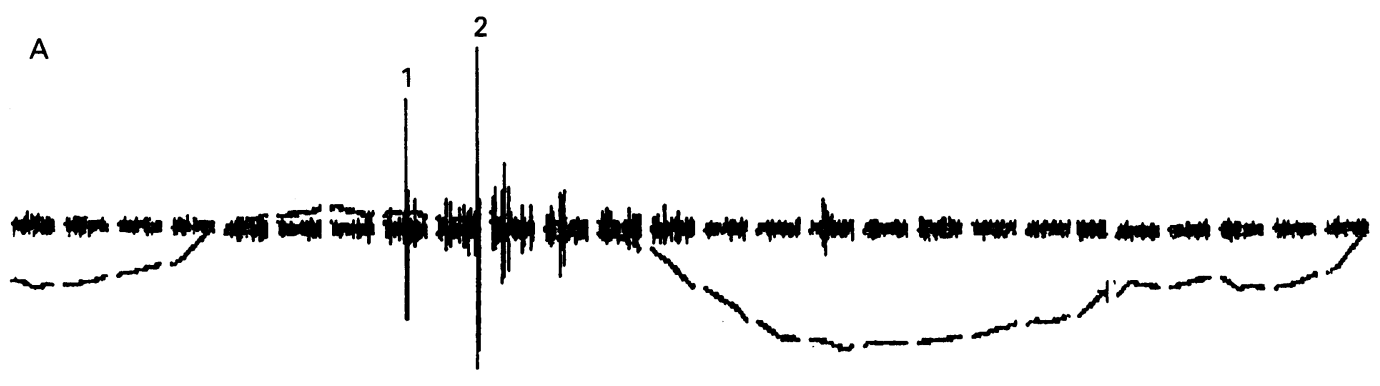

Inspiration

Expiration

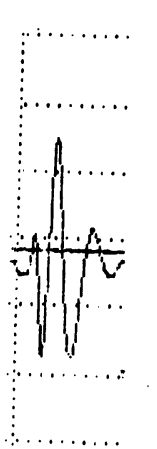

1

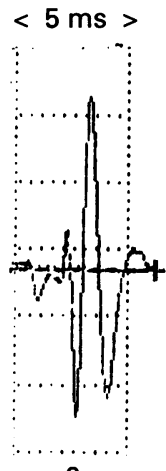

2

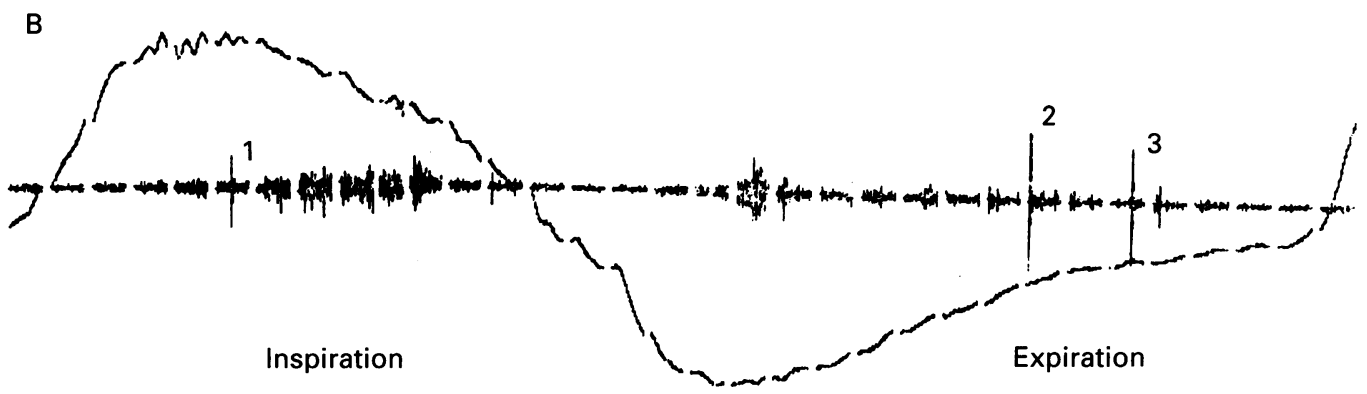

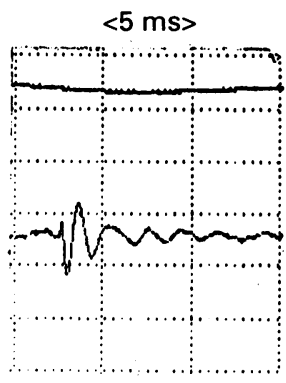

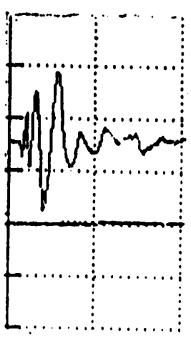

2

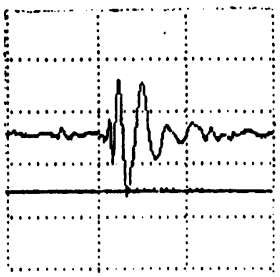

3

Figure 1 (A) Late inspiratory fine crackles typical of asbestosis. The compressed display shows that crackles occur in the second half of inspiration and the expanded display shows the shape of the fine crackles. (B) Mid inspiratory and expiratory crackles associated with pleural thickening. The compressed display shows the timing of the crackles and the expanded display shows the different configuration of the pleural crackles.

and, as in the previously quoted study by Sebastien, ${ }^{6}$ short chrysotile fibres were the most frequent type in the pleura. Diffuse pleural thickening is much more common than plaques in crocidolite workers, supporting the role of amphibole fibres in its causation. ${ }^{34}$

Diffuse pleural thickening often follows episodes of acute pleurisy with effusion. In some cases there is no history of such episodes, but it is probable that they are frequently sub- clinical. ${ }^{3}$ There are features suggestive of an immunological basis for the disease. Sometimes general malaise, occasionally with febrile episodes, accompanies the pleural disease. The erythrocyte sedimentation rate is raised more frequently in patients with diffuse thickening than in those with plaques, and non-specific alterations in serum immunoglobulins occur. ${ }^{35}$

Pathological assessment usually reveals extensive visceral pleural fibrosis, usually most 
marked at the bases but often extending to the apex. It is usually, but not always, bilateral. There are commonly extensive adhesions between the pleura and chest wall. Bands of fibrous tissue may penetrate into the lung and discrete pleural plaques are also often present. Histological examination shows a basket weave pattern of pleural fibrosis. Dense, subpleural, pulmonary parenchymal fibrosis is usually present. ${ }^{32}$

The layer of thickened pleura surrounding the lung and usually adhering to the chest wall impedes expansion of the lungs. In advanced cases there may be a progressively shrinking cuirass of thickened pleura squeezing the lung. The principal symptom is shortness of breath on exertion. There may have been a history of episodes of pleurisy in the past and there may also be pleuritic pain due to adhesions. Pain is occasionally a persistent feature and may be disabling. ${ }^{36}$

On examination there may be reduced chest expansion and quiet breath sounds when the disease is extensive. In some cases crackles may be absent, even when asbestosis is present, due to masking of their audibility by the thickened pleura. Inspiratory crackles may be present, either due to associated asbestosis or to the pleural disease itself. They may be audible but can be detected by time-expanded waveform analysis more frequently. Crackles due to asbestosis are usually repetitive from one respiratory cycle to another and occur almost exclusively during the second half of the inspiratory period. Crackles occur in the absence of evidence of asbestosis of lung tissue on the CT scan in about $40 \%$ of subjects with asbestos-related diffuse pleural thickening and occasionally in those with plaques. ${ }^{37}$ Timeexpanded waveform analysis shows that, although some of the crackles are of similar configuration to those which occur in asbestosis, crackles dissimilar to those which occur in asbestosis are also present. These fine crackles have a distinctive waveform, characteristically occur during mid inspiration and mid expiration, and are repetitive from cycle to cycle (fig 1). The distinctive crackles of pleural disease are probably produced by friction between the pleural layers which is maximal at mid inspiration and mid expiration.

The chest radiograph shows pleural thickening along the chest walls; there appears to be a tendency for thickening to be more extensive on the left which is unexplained. ${ }^{38}$ The costophrenic angles are often obliterated and, when the condition is extensive, the diaphragmatic and cardiac contours may be obscured. Fibrous strands extending from a thickened pleura may have a "crow's feet" appearance. The appearance of "shrinking pleuritis with rounded atelectasis", otherwise known as "folded lung" may be seen. The characteristic features were first described by Blesovsky in three patients who had been exposed to asbestos. ${ }^{39}$ The pleural changes make assessment of the lung fields difficult and definite radiological evidence of asbestosis of the lungs is usually not apparent. The pleural thickening occasionally involves only or mainly the upper lobes, and there may also be fibrosis of the upper lobes of the lungs. ${ }^{4041}$ The radiological appearance may be difficult to distinguish from those of past tuberculosis.

High resolution computed tomographic (HRCT) scanning demonstrates the extent of the pleural thickening more clearly than the plain chest radiograph, particularly in the region of the paravertebral gutter which is very frequently involved and difficult to assess on the plain radiograph. HRCT scanning aids differentiation between multiple discrete plaques and diffuse pleural thickening which can be impossible on plain radiographs. ${ }^{11}$ It is helpful in identifying what may appear to be a mass lesion on the plain radiograph as an area of infolded lung or Blesovsky syndrome (fig 2). When this typical appearance is seen on the HRCT scan a biopsy sample is not generally necessary. HRCT scanning may reveal evidence of asbestosis of lung tissue which is not apparent on the plain radiograph.

The characteristic features of diffuse pleural thickening on lung function testing are a restrictive ventilatory defect, decreased compliance, a reduction in total lung capacity, and impairment of gas transfer characterised by a low carbon monoxide transfer factor (TLCO) with a normal or increased carbon monoxide transfer coefficient $(\mathrm{KCO}) .{ }^{42}$ The latter feature probably reflects the external "squeezing" of the lung characteristic of pleural disease in which a reduction in TLCO is primarily a result of reduction in lung volume rather than derangement of the alveolar tissue. The $\mathrm{KcO}$ correlates directly with the degree of pleural thickening. ${ }^{43}$ This is of importance because a normal Kco in the presence of pleural thickening should not be construed as implying the absence of parenchymal asbestosis; if asbestosis and pleural thickening coexist the Kco may be normal or even increased. ${ }^{43}$

The effect of pleural thickening with diaphragmatic involvement on respiratory muscle function has been investigated. ${ }^{44}$ Respiratory muscle strength, including diaphragm strength, was found to be normal even in patients with pleural disease involving the diaphragms and costophrenic angles. Recoil pressure was high

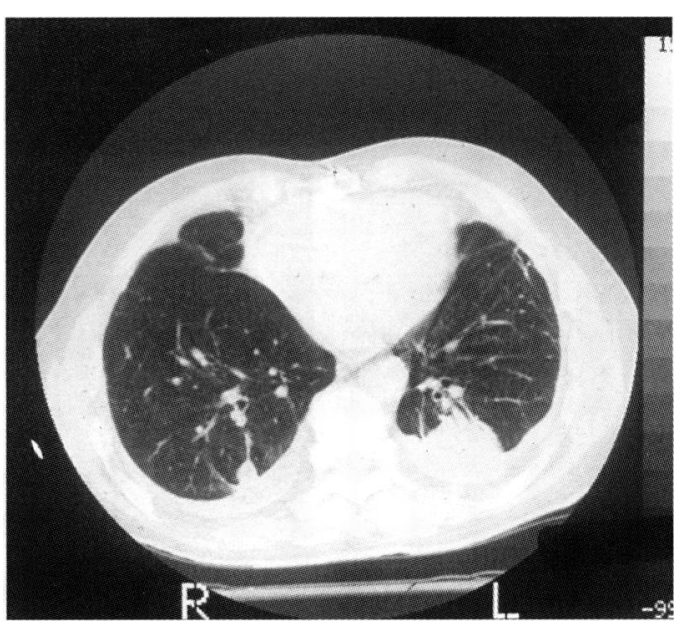

Figure 2 A large pleurally based rounded lesion is seen in the left posterior region with a small lesion in the right posterior region. 
in some subjects and correlated with the radiographic extent of pleural disease. These findings suggest that reduced chest wall compliance rather than respiratory muscle weakness is important in causing breathlessness in patients with pleural thickening.

The degree of impairment of lung function correlates with the extent of pleural disease assessed by CT scanning. ${ }^{114546}$ The severity of breathlessness and disability increase with increasing severity of pleural disease. ${ }^{1147-49} \mathrm{Ob}$ literation of the costophrenic angles and the extent of chest wall pleural thickening are the radiological features best associated with degree of disability. Unilateral disease may cause disability, although it is less severe than that associated with bilateral disease.

Pleural biopsy samples are often not necessary but occasionally there is doubt as to the diagnosis, particularly when the pleural changes are unilateral suggesting the possibility of mesothelioma. Pleural biopsy by Abrams' needle is not advisable in the absence of pleural fluid and, in any case, usually provides too small a sample for adequate diagnosis. More satisfactory biopsy samples may be obtained with a Tru-cut needle or Biopty gun, preferably with
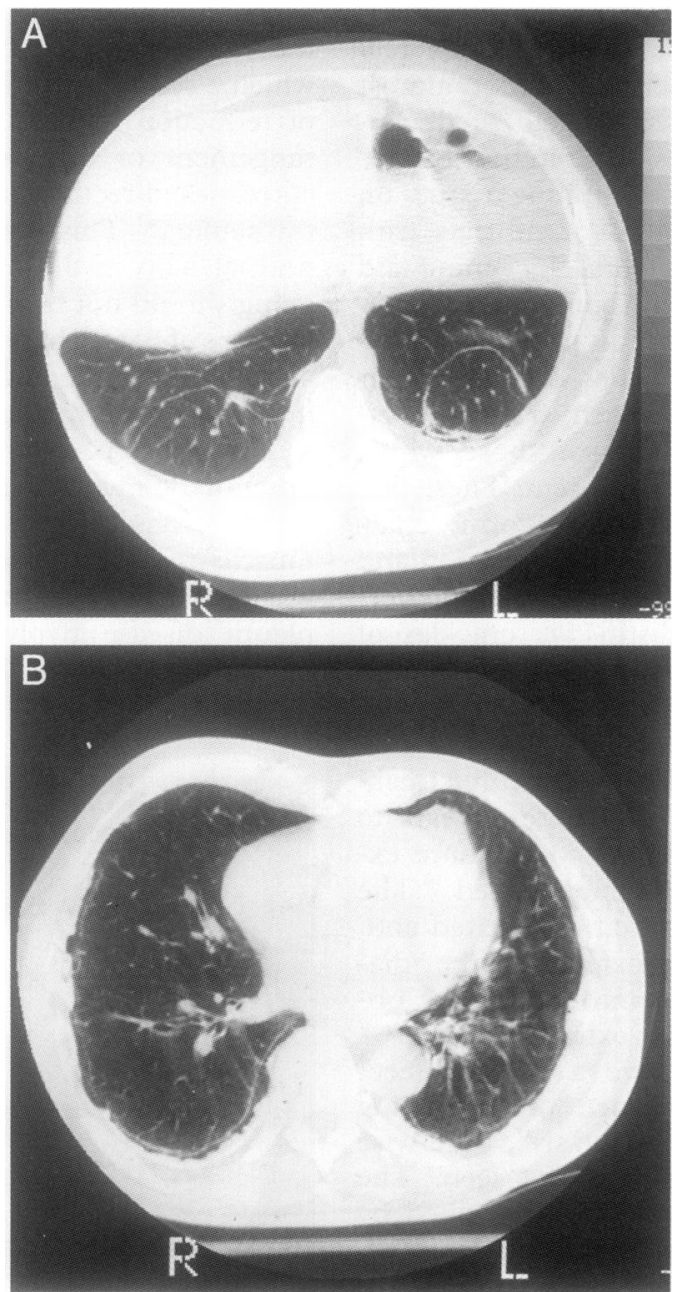

Figure 3 (A) A curvilinear opacity in the left lung which probably represents pleural fibrosis extending into the lung.

The line is well defined and is seen to originate from the pleura. (B) Subpleural curvilinear opacities indicating interstitial fibrosis. The lines are slightly irregular and less clearly defined. ultrasound or CT guidance, although these are also small and hence subject to sampling error so that malignancy may be missed. If an effusion is present and adhesions are not too extensive, thoracoscopy with pleural biopsy under direct vision may be helpful. Sufficient doubt occasionally remains after these procedures for thoracotomy to be undertaken.

In most cases no treatment is advisable. If there is severe impairment of lung function with consequent disability, decortication may be attempted. However, this seldom produces any worthwhile improvement in lung function ${ }^{50}$ and may be followed by persistent chest pain.

Pleural thickening often begins on one side with effusion followed by pleural thickening, to be followed months or years later by a similar episode on the other side. In a study of crocidolite workers it was found that pleural thickening tended to progress gradually, mainly during the first 15 years after its onset. ${ }^{34}$ Smoking does not affect the progression of pleural disease. ${ }^{51}$ Clinically overt asbestosis may eventually emerge. The risks of mesothelioma and lung cancer relate to the degree of exposure to asbestos as in other asbestos-related conditions. A recent study of crocidolite workers from Wittenoom Gorge in Western Australia found that the presence of pleural thickening did not affect the mortality from lung cancer and mesothelioma after allowing for the effects of age, smoking, and degree of asbestos exposure. ${ }^{29}$

\section{Parenchymal changes accompanying pleural disease}

Features suggestive of interstitial fibrosis of lung tissue are not infrequently seen on HRCT scanning in subjects with pleural disease. With diffuse pleural fibrosis there are often strands of pleural fibrosis extending into or across the lung. It is usually possible to distinguish these appearances from features more suggestive of interstitial fibrosis of lung tissue such as subpleural curvilinear opacities (fig $3 \mathrm{~A}$ and $\mathrm{B}$ ).

Parenchymal changes also occur in association with plaques and their interpretation is the subject of debate. One view is that features of interstitial fibrosis on the HRCT scan constitute evidence of asbestosis, while another is that their significance is uncertain and that they should not be regarded as sufficient evidence of asbestosis. In favour of the latter view it is pointed out that the appearances suggesting interstitial fibrosis are sometimes seen only in parts of the lung immediately beneath the pleural lesion (fig 4) and, hence, that the CT appearance may be a manifestation of the pleural disease - for example, pressure causing localised collapse of the underlying lung. The fact that even large plaques are commonly not accompanied by underlying lung opacities weighs against this hypothesis.

Attempts have been made to investigate the pathological nature of parenchymal changes on the CT scan. Ren et al performed HRCT scanning on inflated lungs removed at necroscopic examination from 29 subjects with pleural plaques and 29 without pleural 


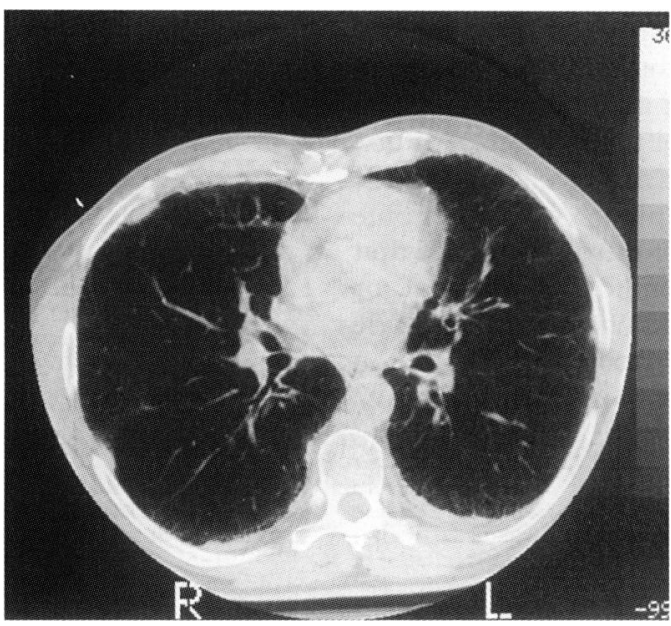

Figure 4 Subpleural curvilinear reticular opacification in the posterior basal part of the right lung beneath the pleural thickening.

plaques. ${ }^{52}$ Each scan slice was evaluated for six characteristics of asbestos-related lung disease: septal thickening, parenchymal linear densities, curvilinear subpleural lines, subpleural dependent densities, honeycombing, and visceral pleural thickening. The lungs were then sectioned along the planes of each scan slice to allow comparison between histological and radiographic features. Septal thickening and parenchymal linear densities were seen more often in cases with plaques than in controls, although the differences were not statistically significant, but curvilinear subpleural lines were seen in four of the cases with plaques and not in any of 29 controls. Histological examination revealed non-specific peribronchiolar fibrosis in most subjects in both groups, and its presence was not predicted by the features on the HRCT scan suggesting asbestosis. A histological diagnosis of asbestosis was made in only two of the cases with plaques, reflecting the low frequency of exposure to asbestos in the group; only seven of 29 gave a history of definite exposure to asbestos and there was no difference in mean fibre counts between the group with plaques and the controls. The authors concluded that pleural plaques are not predictive of the presence of asbestosis and that HRCT scanning does not accurately diagnose asbestosis as assessed histologically. However, the low prevalence of exposure to asbestos limits the value of this study in assessing the predictive value of features on the HRCT scan for the presence of histological evidence of asbestosis; in a group with a high prevalence of sufficient asbestos exposure to cause asbestosis the positive predictive value for asbestosis of features of interstitial fibrosis on the HRCT scan would be much higher.

Another study correlated pathological and HRCT findings on necropsy lungs from seven patients with established asbestosis. ${ }^{53}$ The appearances on the HRCT scan were studied in parts of the lungs which showed histological features of early asbestosis. Subpleural dot and branch structures on the HRCT scans corresponded to peribronchiolar fibrosis with involvement of alveolar ducts, pleural- based nodular opacities corresponded to subpleural fibrosis, subpleural curvilinear lines or bands corresponded to areas of peribronchiolar fibrosis joined by collapse and fibrosis of alveoli, and hazy patches of increased attenuation corresponded to mild alveolar wall and interlobular septal thickening due to fibrosis. These HRCT features, regarded as characteristic of asbestosis, were very seldom seen in a group of 17 control subjects and, when they did occur, they were of minimal extent. These results suggest that HRCT features of asbestosis are reliable indicators of histological features of asbestosis in subjects with substantial exposure to asbestos.

The term "early asbestosis" is often used to refer to HRCT appearances suggesting minimal or mild interstitial fibrosis with the implication that progression is likely to occur. There is some evidence to support this proposition. A study of subjects with asbestosis found that, in cases with mild parenchymal abnormalities, the subpleural curvilinear opacity tended to occur in the posterior parts of the lower lobe, but in cases with more advanced fibrosis with honeycombing in the posterior regions curvilinear opacities tended to be distributed elsewhere. ${ }^{54}$ These observations suggest that the subpleural curvilinear opacity represents an early stage of asbestosis which later develops into subpleural honeycombing on the HRCT scan. In another study ${ }^{55}$ serial HRCT scans performed 12-37 months apart showed definite progression of HRCT features of asbestosis in eight of 15 subjects. However, it is by no means certain that changes of "early asbestosis" on the HRCT scan necessarily presage the subsequent emergence of classical asbestosis apparent on clinical examination and plain radiography, and the results of long term follow up studies of subjects previously identified as having asbestosis only by HRCT scanning will be needed for a final judgement on this point.

\section{Pericarditis}

Exposure to asbestos occasionally causes benign pericardial effusion, thickening, and calcification. ${ }^{56}$ These manifestations are analogous to the effects of asbestos on the pleura, and pericardial disease is usually associated with pleural disease. The pericardial thickening may result in constrictive pericarditis with functional consequences of impaired right ventricular filling. This may be suspected in patients with breathlessness which appears disproportionately severe for the degree of apparent respiratory functional impairment. Anatomical and functional aspects of pericardial constriction may be demonstrated by magnetic resonance imaging. ${ }^{57}$

\section{Man-made mineral fibres}

The question of whether man-made mineral fibres may cause pleural and pulmonary changes analogous to those caused by asbestos has been raised. A study of 284 workers with 20 or more years' exposure to fibreglass reported pleural plaques or thickening in a total of 20 
subjects. ${ }^{58}$ However, four of these reported some exposure to asbestos also, only just over half the identified cohort agreed to be studied, and there was no control population. A much larger survey of workers in seven man-made mineral fibre production plants, with other blue collar workers serving as controls, reported that there were no adverse clinical, functional, or radiographic effects of exposure to man-made mineral fibres, although specific comment upon pleural abnormalities was not made..$^{59}$

1 Harries PG, Mackenzie FA, Sheers G, Kemp JH, Oliver TP, Wright DS. Radiological survey of men exposed to
asbestos in naval dockyards. $B r \mathcal{F}$ Ind Med 1972;29:274-9.

2 Lilis R, Miller A, Godbold J, Chan E, Selikoff IJ. Radiographic abnormalities in asbestos insulators: effects of duration from onset of exposure and smoking. Relationships of dyspnea with parenchymal and pleural fibrosis. Am ₹ Ind Med 1991;20:1-15.

3 Hillerdal G. Non-malignant asbestos pleural disease. Thorax 1981;36:669-75.

4 Epler GR, McLoud T, Gaensler EA. Prevalence and in cidence of benign asbestos pleural effusion in a working population. $7 A M A$ 1982;247:617-22.

5 Selikoff IJ. The occurrence of pleural calcification among asbestos insulation workers. Ann NY Acad Sci 1965;132: 351-67.

6 Sebastien P, Janson X, Gaudichet A. Asbestos retention in human respiratory tissues: comparative measurements in lung parenchyma and in parietal pleura. In: Wagner JC, Davis W, eds. Biological effects of mineral fibres. Vol 1. Lyon: IARC Scientific Publications No 30, 1980:237-46.

7 Suzuki Y, Kohyama N. Translocation of inhaled asbestos fibers from the lung to other tissues. Am ₹ Ind Med 1992; 19:701-4.

8 Taskinen E, Ahlman K, Wiikeri M. A current hypothesis of the lymphatic transport of inspired dust to the parietal the lymphatic transport of

9 Churg A, Vedal S. Fiber burden and patterns of asbestosrelated disease in workers with heavy mixed amosite and chrysotile exposure. Am $\mathcal{F}$ Respir Crit Care Med 1994;150 $663-9$

10 Hourihane DO'B, Lessof L, Richardson PC. Hyaline and calcified pleural plaques as an index of exposure to asbestos. A study of radiological and pathological features of 100 cases with a consideration of epidemiology. BMF 1966;1:1069-74.

11 Al Jarad N, Poulakis N, Pearson MC, Rubens MB, Rudd RM. Assessment of asbestos induced pleural disease by computed tomography-correlation with chest radiograph computed tomography-correlation with chest

12 Hjortsberg U, Orbaek P, Arborelius M Jr, Ranstam J, Welinder H. Railroad workers with pleural plaques: II. Small airway dysfunction among asbestos-exposed workers. $A n$ f Ind Med 1988;14:643-7.

13 Kilburn KH, Warshaw R. Pulmonary functional impairmen associated with pleural asbestos disease: circumscribe and diffuse thickening. Chest 1990;98:965-72.

14 Hedenstierna G, Alexandersson R, Kolmodin-Hedman B, Szamosi A, Tollqvist J. Pleural plaques and lung function in construction workers exposed to asbestos. Eur $\mathcal{F}$ Respir Dis 1981;62:111-22.

15 Kilburn $\mathrm{KH}$, Warshaw RH. Abnormal lung function associated with asbestos disease of the pleura, the lung and both: a comparative analysis. Thorax 1991;46:33-8.

16 Kilburn KH, Warshaw RH. Abnormal pulmonary function associated with diaphragmatic pleural plaques due to exposure to asbestos. Br F Ind Med 1990;47:611-4.

17 Oliver LC, Eisen EA, Greene R, Sprince NL. Asbestosrelated pleural plaques and lung function. $\mathrm{Am} \mathcal{f}$ Ind $\mathrm{Med}$ 1988;14:649-56.

18 Bourbeau J, Ernst P, Chrome J, Armstrong B, Becklake MR. The relationship between respiratory impairmen and asbestos-related pleural abnormality in an active workforce. Am Rev Respir Dis 1990;142:837-42.

19 Wright JL, Churg A. Severe diffuse small airways abnormalities in long term chrysotile asbestos miners. $\mathrm{Br}$ Ind Med 1985;42:556-9.

20 McMillan GHG, Rossiter CE. Development of radiological and clinical evidence of parenchymal fibrosis in men with non-malignant asbestos-related pleural lesions. $B r f$ Ind Med 1982;39:54-9.

21 Lilis R, Ribak J, Suzuki Y, Pennet L, Bernstein N, Selikof IJ. Non-malignant chest $\mathrm{X}$-ray changes in patients with mesothelioma in a large cohort of asbestos insulation workers. Br $\mathcal{F}$ Ind Med 1987;44:402-6.

22 Edge JR, Incidence of bronchial carcinoma in shipyard workers with pleural plaques. Ann NY Acad Sci 1979;330 289-94.

23 Weiss W. Asbestos-related pleural plaques and lung cancer Chest 1993;103:1854-9.

24 Eisenstadt HB. Benign asbestos pleurisy. FAMA 1965;192 419-21.

25 Martensson G, Hagberg S, Pettersson K, Thiringer G Asbestos pleural effusion: a clinical entity. Thorax 1987 42:646-5i

26 Lilis R, Lerman Y, Selikoff IJ. Symptomatic benign pleura effusions among asbestos insulation workers: residual radiographic abnormalities. Br f Ind Med 1988;45:443-9. 27 Gaensler EA, Kaplan AI. Asbestos pleural effusion. Ann Intern Med 1971;74:178-91.

28 Shore B. Daughaday CC, Spilberg I. Benign asbestos pleurisy in the rabbit: a model for the study of pathogenesis. Am Rev Respir Dis 1983;128:481-5.

29 de Klerk NH, Musk AW, Cookson WOCM, Glancy JJ, Hobbs MST. Radiographic abnormalities and mortality in subjects with exposure to crocidolite. $\mathrm{Br} F$ Ind $\mathrm{Med}$ 1993;50:902-6.

30 Finkelstein MM. A study of dose-response relationships for asbestos associated disease. BrF Ind Med 1985;42:319-25.

31 Roggli VL, Pratt PC, Brody AR. Asbestos content of lung tissue in asbestos associated diseases: a study of 110 cases. tissue in asbestos associated disea

32 Gibbs AR, Stephens M, Griffiths DM, Blight BJN, Pooley FD. Fibre distribution in the lungs and pleura of subjects with asbestos related diffuse pleural fibrosis. $\mathrm{Br} f$ Ind $\mathrm{Med}$ 1991;48:762-70.

33 Wagner JC, Moncrieff CB, Coles R, Griffiths DM, Munday DE. Correlation between fibre content of the lungs and disease in naval dockyard workers. Br f Ind Med 1986;43 391-5.

34 de Klerk NH, Cookson WOC, Musk AW, Armstrong BK, Glancy JJ. Natural history of pleural thickening after exposure to crocidolite. $\mathrm{Br}$ F Ind Med 1989;46:461-7.

35 Hillerdal G. Asbestos related pleuropulmonary lesions and the erythrocyte sedimentation rate. Thorax 1984;39:752-8.

36 Miller A. Chronic pleuritic pain in four patients with asbestos induced pleural fibrosis. $\mathrm{Br}$ f Ind Med 1990;47:147-53.

37 Al Jarad N, Davies SW, Logan-Sinclair R, Rudd RM. Lung crackle characteristics in patients with asbestosis, asbestosrelated pleural disease and left ventricular failure using a time-expanded waveform (TEW) analysis. Respir Dis 1994;88:37-46.

$38 \mathrm{Hu} \mathrm{H}$, Beckett L, Kelsey K, Christiani D. The left-sided predominance of asbestos-related pleural disease. Am Rev Respir Dis 1993;148:981-4.

39 Blesovsky A. The folded lung. $\mathrm{Br} f$ Dis Chest 1966;60: 19-22.

40 Oliver RM, Neville E. Progressive apical pleural fibrosis: a 'constrictive' defect. Br f Dis Chest 1988;82:439-43.

41 Hillerdal G. Pleural and parenchymal fibrosis mainly affecting the upper lung lobes in persons exposed to asbestos. Respir Med 1990;84:129-34.

42 Schwartz DA, Galvin JR, Dayton CS, Stanford W, Merchan JA, Hunninghake GW. Determinants of restrictive lung in asbestos-induced pleural fibrosis. F Appl Physiol 1990; 68:1932-7.

43 Cookson WOC, Musk AW, Glancy JJ. Pleural thickening and gas transfer in asbestosis. Thorax 1983;38:657-61.

44 Al Jarad N, Carroll MP, Laroche C, Poulakis N, Moxham $\mathrm{J}$, Green $\mathrm{M}$, et al. Respiratory muscle function in patients with asbestos-related pleural disease. Respir Med 1994;88: 115-20.

45 Al Jarad N, Wilkinson P, Pearson MC, Rudd RM. A new high resolution computed tomography scoring system for
pulmonary fibrosis, pleural disease and emphysema in pulmonary fibrosis, pleural disease and emphysema in
patients with asbestos related disease. Br f Ind Med 1992; patients with

46 Schwartz DA, Galvin JR, Yagla SJ, Speakman SB, Merchant JA, Hunninghake GW. Restrictive lung function and asbestos-induced pleural fibrosis; a quantitative approach f Clin Invest 1993;91:2685-92.

47 Britton MG. Asbestos pleural disease. Br 7 Dis Chest 1982 76:1-10.

$48 \mathrm{McGavin}$ CR, Sheers G. Diffuse pleural thickening in asbestos workers: disability and function. Thorax 1984;39: 604-7.

49 Lilis R, Miller A. Godbold J, Chan E, Selikoff IJ. Pulmonary function and pleural fibrosis: quantitative relationships with an integrative index of pleural abnormalities. $A m g$ with an integrative index

50 Dernevik L, Gatzinsky P. Long term results of operation for shrinking pleuritis with atelectasis. Thorax 1985;40 448-52.

51 Yano EY, Tanaka K, Funaki M, Maeda K, Matsunaga C, Yamaoka K. Effect of smoking on pleural thickening in asbestos workers. Br $\mathcal{F}$ Ind Med 1993;50:898-901.

52 Ren H, Lee DR, Hruban RH, Kuhlman JE, Fishman E, Wheeler K, et al. Pleural plaques do not predict asbestosis: high-resolution computed tomography and pathology study. Modern Pathol 1991;4:201-9.

53 Akira M, Yamamoto S, Yokoyama K, Kita N, Morinaga K, Tokuro $\mathrm{H}$, et al. Asbestosis: high resolution CT-pathologic correlation Radiology 1990;176:389-94.

54 Yoshimura $H$, Hatakeyama $M$, Otsuji $H$, Maeda $M$, Ohishi $\mathrm{H}$, Uchida $\mathrm{H}$, et al. Pulmonary asbestosis: CT study of
subpleural curvilinear shadow. Thorac Radiol 1986;158: subpleural

55 Akira M, Yokoyama K, Yamamoto S, et al. Early asbestosis: evaluation with high resolution CT. Radiology 1991;178: 409-16.

56 Davies D, Andrews MIJ, Jones JSP. Asbestos induced pericardial effusion and constrictive pericarditis. Thorax 1991 46:429-32.

57 Al Jarad N, Underwood SR, Rudd RM. Asbestos-related pericardial thickening detected by magnetic resonance imaging. Respir Med 1993;87:309-12.

58 Kilburn KH, Powers D, Warshaw RH. Pulmonary effects of exposure to fine fibreglass: irregular opacities and small airways obstruction. Br ₹ Ind Med 1992;49:714-20.

59 Hughes JM, Jones RN, Glindmeyer HW, Hammad YY, Weill $\mathrm{H}$. Follow up study of workers exposured to man made mineral fibres. Br f Ind Med 1993;50:658-67. 